\title{
Open Government Data in Hungary
}

\section{Anna Orbán ${ }^{1}$}

\section{Abstract}

DOI: 10.24989/ocg.v331.31

Today it is increasingly evident that data is the new determining element in the economy and society. Digital data is essential resources for economic growth, competitiveness, innovation, job creation and social development.

For well-founded decisions, real data containing all the necessary information are required. Public organizations are obliged to collect and store vast amounts of data. However, the question arises: who has access to them and for what purposes are they used for?

Open Data has become increasingly prevalent both on organizational and national levels. By making the datasets available to the public, institutions have become more transparent, efficient and more economical. There are EU and national strategies and programs to support open public administration by providing an appropriate legal environment and recommending practical measures.

Freedom of information guarantees the accessibility of public data. However, accessibility is blocked by several challenges and obstacles, such as traditional approaches, legal constraints, practical and technical problems.

The aim of this paper is to interpret the basic concepts of open government data, and present some of the problems of Hungarian data policy, legal regulations and practical implementations.

\section{Data of public interest and/or open data}

In Hungary, the protection of personal data and the publicity of data of public interest have been fundamental rights enshrined in the Constitution since 1989. „Everyone shall have the right to the protection of his or her personal data, as well as to access and disseminate data of public interest." [7, Sections 59 and 61.] [16, Article VI (2) $]^{2}$

The concepts of personal data and data of public interest have been present in Hungarian law for almost three decades, but their interpretation and practical application are still not uniform.

\section{Personal data}

"Personal data shall mean data relating to the data subject, [...] as well as conclusions drawn from the data in regard to the data subject." [4, Section 2(1)] [3, Section 3(2)]

\footnotetext{
${ }^{1}$ National University of Public Services, 2 Ludovika sqr., H-1083 Budapest, Hungary, e-mail: orban.anna@uni-nke.hu

${ }^{2}$ All translations of Hungarian laws by the author.
} 
The main rule is confidentiality and privacy. Personal data is protected and manageable only for specific purposes, including the exercise of a right and the fulfilment of obligations, with the right of informational self-determination ensured.

\section{Data of public interest}

"Data of public interest shall mean data, other than personal data, that are managed by a body or person performing central or local governmental tasks or other public tasks defined by law [...]" $[4$, Section 2(4)] [3, Section 3(5)]

The main rule is to ensure publicity, as well as the transparency of public finances and the management of national assets. The term does not include any privately held data of public interest. Data of public interest is not equivalent to Open Data, as access to the former can be restricted (e.g. classified data, business secrets, data required for decision making, restrictions motivated by defense or national security interests, etc.).

\section{Data public on reasons of public interest (since 2004)}

"Data public on reasons of public interest shall mean any data, other than public information, that are prescribed by law to be published, made available or otherwise disclosed for the benefit of the general public. " [3, Section 3(6)]

Data public on reasons of public interest include certain personal data of individuals acting within the scope of responsibilities and authority of a body undertaking public duties, such as their name, function, job position, executive mandate and other personal data as defined by law.

Business data may also be public on reasons of the public interest, if businesses use public funds or state budgets, or have a contract with a state body or a local government.

\section{Regulatory environment}

The European Union (EU), the United Nations (UN), the Organization for Economic Co-operation and Development (OECD), the World Bank and other organizations have developed and issued many strategies, initiatives and documents to open up government data. Over the past decade, national governments have also developed their strategies and regulatory documents to manage and access public data.

In Hungary, data creation, data management, data usage and data provision appear in a number of laws. From the point of view of access to and use of public data, it is useful to take a closer look at some of them.

The constitutional amendment promulgated on October 23, 1989 created the constitution of the republic, which first raised the protection of personal data and freedom of information on constitutional level in Central and Eastern Europe. [7, Sections 59 and 61]

The Data Protection Act adopted after long preparations in 1992 was an up-to-date and Europeanstyled law at that time. 
The Act

- defined the notion of personal data, public interest data and later data public on grounds of public interest,

- $\quad$ ordered the protection of personal data,

- defined the rules for accessing public interest data,

- regulated the institution of data protection supervisor and data protection register,

- $\quad$ and finally its amendment adopted in 2003 ensured consistency with the European Parliament and Council Data Protection Directive 95/46/EC. [4]

When the PSI Directive (officially Directive 2003/98/EC [10]) entered into force, Hungary was not yet a full member of the European Union. After accession, the Hungarian government considered that the then constitution, regulation of data protection and electronic freedom of information fully complied with the EU acquis. Act XC of 2005 on the freedom of information provided for the electronic publication of data of public interest and the publication of legal and judicial decisions. [6] The 305/2005 (XII. 25.) government decree contained detailed rules for publication. [2]

The Council of Europe Convention on Access to Official Documents was signed by the Hungarian government in 2009 and ratified in 2010. With these moves, Hungary expressed its commitment to the democratic principle of transparency in state operations. The scope of the Convention is narrower than the scope of natural and legal entities to which the requirement of publicity of the data of public interest and, in particular, the right of access to official documents, is extended by Hungarian law.

In the latter, the definition of "public authorities" includes the following:

1. legislative bodies as regards their other activities,

2. judicial authorities as regards their other activities,

3. natural or legal persons insofar as they perform public functions or manage public funds, according to national law. [8]

After nearly two decades, in 2011, the old Data Protection Act was replaced by a new Privacy Act. The Privacy Act has a decisive role in the data ecosystem, with many other laws referring to it. When it was drafted, the provisions of the PSI Directive were known, but legal harmonization had not yet taken place.

The Act

- $\quad$ interprets the most important definitions,

- $\quad$ provides for the protection of personal data,

- defines the rules for access to data of public interest, 
- $\quad$ requires disclosure of data of public interest, and the operation of the central electronic register of public information and the single data retrieval system,

- $\quad$ setting up a new data protection authority, the National Authority for Data Protection and Freedom of Information (NAIH) instead of the data protection supervisor, creating rules on the status and responsibilities of the authority. [3]

In 2012, the new Public Data Act (Act LXIII of 2012) has been aligned with the 2003 PSI Directive (with a delay of several years). The 2013 amendment to the PSI Directive (Directive 2013/37/EU [11]) implied new tasks. The amendments to the Privacy Act and the Public Data Act (Act XCVI of 2015) brought the relevant laws in line with the EU acquis. The Public Data Act currently complies with the PSI Directive.

The Act

- defines the principles for the reuse of public data,

- $\quad$ regulates the process of re-using, remuneration and format requirements,

- $\quad$ stipulates the conclusion of a reuse agreement,

- $\quad$ contains special rules for the reuse of cultural public information.[5]

Legal harmonization with the European General Union Data Protection Regulation (GDPR [12]) is a task for 2018. Although there are only a couple of months left until the May $25^{\text {th }}, 2018$ entering into force of the GDPR, there is only a draft amendment as per March 2018, still to be submitted to Parliament.

Hungarian public data are regulated by a fairly large number of laws whose relevance and consistency must be ensured. Over the past few years, the PSI Directive has been formally implemented, but the government still has to issue the executive orders and establish uniform and correct practices.

\section{Access to public data}

Public interest data are published on several levels:

- $\quad$ based on the obligation of publication by electronic means,

- $\quad$ based on data requests, such as

- data requests of public interest,

- data requests for statistical analyses or scientific research.

- data requests under a public data reuse agreement. 
General provisions on access to information of public interest shall not apply to the disclosure of information from official records that is subject to the provisions of a separate law.

\subsection{Obligation of publication by electronic means}

Access to public information whose publication is rendered mandatory under Act CXII of 2011 shall be made available through the internet, in digital format, to the general public without any restriction, in a manner not to allow the identification of specific individuals, in a format allowing for printing or copying without any loss or distortion of data, free of charge, covering also the functions of consultation, downloading, printing, copying and network transmission (hereinafter referred to as "electronic publication"). The range of data is defined by the publication lists (organizational and personal data, activity, operation data, and management data).

Access to data on the publication lists can be provided on a centralized website or on the organizations own websites and on the public data portal. These portals do not directly support the reuse of data. It is also a problem that most data are not machine-readable, cannot be queried en masse, are not available with open licenses, or in some cases their timeliness is questionable.

According to the Privacy Act, anyone has access to the public data issued by the public organizations obliged for that as well as to references to such data by using the Public Data Finder (http://kozadat.hu/kereso/). Although since 2008 all public bodies have been obliged to provide data, many of them have fulfilled this obligation only partially, if at all. The proportion of regular data providers is low. ${ }^{3}$

Further efforts are needed to open public data so that anyone can access them for personal or business purposes. Simple publishing data is not enough to make them useful. Citizens and businesses are not interested in the data themselves, but the services that are being implemented on that basis.

\subsection{Access to public information upon request}

The procedure is regulated by the Privacy Act (Sections 28-31).

Data of public interest and data public on grounds of public interest shall be made available to anyone upon a request presented verbally, in writing or by electronic means.

Access to data of public interest is hindered by several factors. The deadline for making the data available is 15 days. The body with public service functions that has the data of public interest on record is not obliged to comply with requests for public information if the requesting party does not provide his/her name, or a legal person fails to provide its name and contact details through which the requested dataset or any other information can be provided. This regulation eliminates the possibility of anonym data requests. Fulfilling a repeated data request for the same dataset by the same claimant within a year is not mandatory. The data used for decision making by a public service body are not public for ten years from the date of their creation. Such decisions may be rejected even after the decision has been made if the data concerned are used for substantiating further decisions. The Privacy Act also significantly expanded the scope of chargeable costs.

\footnotetext{
${ }^{3}$ Up to 6500 organizations have provided data on the kozadat.hu portal. On January 1, 2018, in the public repository, 2812 institutions could be searched for 153,098 records. [14]
} 
In determining the chargeable fee, the following cost items can be taken into account:

- the cost of the data storage device containing the requested information,

- the costs of delivery of such device to the requesting party,

- $\quad$ if the fulfilment of the request for information requires the deployment of disproportionate workforce, the additional labor costs can also be charged.

The rules for determining reimbursement are still missing.

\subsection{Data request for reuse}

The procedure is regulated by the Public Data Act (Sections 10-18).

Applicants may initiate the procedure by submitting a written request. The request shall contain:

- $\quad$ an explicit declaration that the public data indicated are requested for reuse;

- $\quad$ the applicant's name, postal address (registered office), telephone number and e-mail address;

- $\quad$ an exact specification of the public data requested for reuse;

- the desired format of the public data requested for reuse, including an indication of the technical means and the method which the applicant intends to use;

- $\quad$ the required frequency, if recurrent access is requested.

The application may be rejected if the public data concerned cannot be made available for reuse, are not available at all and cannot be procured from another public body either. The public body shall conclude a reuse agreement with the applicant about releasing public sector information for reuse. A public body may charge a fee for making available for reuse the public sector information managed by it. The applicable fee shall not exceed the marginal cost of collecting, producing, processing and distributing the public data.

The rules for determining reimbursement are also missing here.

If a request is rejected, the applicant may appeal to the National Authority for Data Protection and Freedom of Information (NAIH) or opt for a court action.

\section{Data policy}

In 2012, Hungary joined the Open Government Partnership (OGP) initiative. One of the commitments assumed was to improve the publicity of data of public interest and data public on grounds of public interest in accordance with the principles of the Privacy Act. The progress report on Hungary established that a large majority of local governments failed to comply with the publicity obligation and the information published was often of bad quality and not searchable by IT means due to their format. In addition, there was a lack of real and meaningful cooperation 
between the government and civil organizations, which eventually led to the exit of the Hungarian government from the OGP at the end of 2016. [15]

Before that move, under Government Decision 1310/2015. (V. 21.), a White Paper on National Data Policy was compiled that recommended both a national data policy strategy and concrete measures. [1]

This vision outlined in the White Paper fully complies with the goals specified by the National Infocommunication Strategy and the Public Administration and Public Service Development Strategy, as well as with the EU initiatives. Although Hungary has not formally adopted a national data policy, the latter's objectives will appear in the Digital Success Program 2.0 as part of the development of the digital state.

The policy of reuse of public sector data and the protection of national data assets would be an important dimension of the state's role within a digital ecosystem.

Based on NHIT's earlier White Paper, the public policy strategy, prepared in accordance with DJP 2.0, aims at jointly analyzing these two aspects, coordinating and balancing foreign best practices and Hungarian government efforts.

In order to substantiate the strategy, there is a need for

- $\quad$ creating a data cadaster in the public sector;

- $\quad$ developing a public sector data management model;

- $\quad$ evolving a concept of the use of public sector data assets;

- $\quad$ measuring organizational maturity related to the reuse of public sector data;

- $\quad$ compiling best practices abroad and home. [9, pp. 104.]

According to current plans, further research is required for drafting a strategy that covers both a national data policy and the reuse of public data, recommending legislation and measures to develop public administration. [9, pp. 102-105.]

\section{Summary}

Data are essential resources for economic growth, competitiveness, innovation, creation and society's progress in general. The aim of international organizations and individual states is to establish a well-functioning and efficient data ecosystem. Over the recent years Hungary has launched several data policy initiatives, but it still has no national data strategy. The publicity of public sector data is a fundamental right, but in practice, access to data and the utilization of data are hampered by a number of factors.

Some key concepts are not interpreted uniformly, with the Hungarian terms differing from definitions of the PSI directive. Instead of the concept of public sector information (PSI), Hungarian legislation usually applies the concepts of public data (data of public interest and data public on grounds of public interest). 
Although the publicity and reuse of public data is provided by law, their practical application is difficult. There is no real open data portal for Hungary. The practice of requesting public data and data for reuse is not mature. The publicity of public interest data is a fundamental right, and the transparency of public sector operations and the spending of public funds should be guaranteed. Reusing typically involves large amounts of data, usually in a regular and profit-oriented manner. The detailed regulations of the data requirements have still to be elaborated.

To develop a well-functioning data ecosystem at national level, it is necessary to develop a unified government data strategy and then make well-considered measures. The White Paper is a good basis for this, as it integrates the principles of the production and utilization of national data assets, emphasizing the role of open data. Upon drafting a national data strategy, foreign and domestic good practices and initiatives by the European Union should be taken into account, in line with the PSI, INSPIRE and GDPR directives.

\section{References}

[1] 1310/2015 (V.21.) Government Decision on measures required for the wide-scale reuse of public sector information.

[2] 305/2005 (XII. 25.) Government decree on specific provisions relating to the electronic publication of Public Sector Information (PSI), the single PSI search service on inventory and data integration.

[3] Act CXII of 2011 on the right of informational self-determination and on freedom of information (Privacy Act).

[4] Act LXIII of 1992 on the Protection of Personal Data and the Publication of Data of Public Interest (Old Data Protection Act).

[5] Act LXIII of 2012 on the re-use of Public Sector Information.

[6] Act XC of 2005 on the freedom of information.

[7] Constitution of Hungary (the amendment proclaimed on 23 October 1989).

[8] Council of Europe. (2009). Council of Europe Convention on Access to Official Documents (CETS No.205). Tromsø. Retrieved 02 20, 2018, from https://www.coe.int/en/web/ conventions/full-list/-/conventions/treaty/205/signatures?p_auth=Y8QKEMS5

[9] Digital Success Programme 2.0. (2017). Budapest. Retrieved 02 20, 2018, from http://www.kormany.hu/download/6/6d/21000/DJP20\%20Stratégiai\%20Tanulmány.pdf

[10] European Commission. (2003). Directive 2003/98/EC of the European Parliament and of the Council of 17 November 2003 on the re-use of public sector information. Official Journal of the European Union, 90-96.

[11] European Commission. (2013). Directive 2013/37/EU of the European Parliament and of the Council of 26 June 2013 amending Directive 2003/98/EC on the re-use of public sector information. Official Journal of the European Union, 1-8. 
[12] European Commission. (2016). Regulation (EU) 2016/679 of the European Parliament and of the Council of 27 April 2016 on the protection of natural persons with regard to the processing of personal data and on the free movement of such data, and repealing Directive 95/46/EC (General Data Protection Regulation - GDPR). Official Journal of the European Union, 1-88.

[13] NHIT. (2016). White Paper on National Data Policy. Budapest: National Council for Telecommunications and Information Technology. Retrieved 12 28, 2017, from http://nhit.hu/dokumentum/175/Adatpolitikai_feher_konyv_2016081_EN_20161121.pdf

[14] NISZ (National Infocommunications Service Company). (2018, 01 01). About. Retrieved 01 10, 2018, from Public repository: http://kozadattar.hu/node/5

[15] OGP. (2017, 12 28). Hungary (withdrawn). Retrieved 01 15, 2018, from Open Government Partnership: https://www.opengovpartnership.org/countries/hungary-withdrawn

[16] The Fundamental Law of Hungary (updated version of 1 July, 2016). 